\title{
Feeding Obturator with Presurgical Nasoalveolar Molding for a 2 Day Old Neonate with Cleft Lip and Palate
}

Anil Kumar ${ }^{1}$, Rajender Reddy $E^{2}$, Thabitha Rani $\mathrm{S}^{3}$, Kiranmayi $\mathrm{M}^{4}$, Srujana MP5

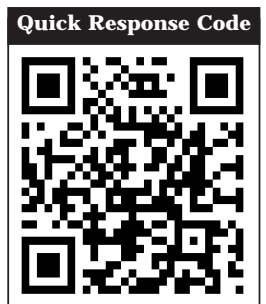

doi: $10.5866 / 2017.9 .10120$

${ }^{1}$ Post Graduate Student

${ }^{2}$ Prof \& HOD

${ }^{3}$ Professor

${ }^{4}$ Reader

${ }^{5}$ Senior Lecturer

Department of Pedodontics

Kamineni Institute of Dental Sciences,

Sreepuram, Narketpally, Nalgonda (Dt).

\section{Article Info:}

Received: April 8, 2017

Review Completed: May 9, 2017

Accepted: J une 10, 2017

Available Online: J une, 2017 (www.nacd.in)

(c) NAD, 2017 - All rights reserved

\section{Email for correspondence:}

anilk3878@gmail.com

\begin{abstract}
:
Cleft lip and Cleft palate is a congenital anomaly involving the orofacial region which may be associated with the malformation or agenesis of the teeth close to the cleft. Prevalence of cleft lip and palate varies from 1:500 to 1:2500 live births. In infants with deft lip and palate, feeding is very difficult which includes nasal regurgitation of food, excessive air intake which results in frequent choking and difficulty in closing their mouth around the nipple or the bottle to make a seal. So an appliance that is favourable for feeding in these children i.e; a feeding obturator should begiven. The present case report presents an infant with cleft lip and palate in which a feeding obturator was fabricated and inserted.
\end{abstract}

Key words: Cleft lip, Cleft palate, feeding obturator

\section{Introduction}

Cleft lip and Cleft palate is a congenital anomaly involving the orofacial region which may be associated with the malformation or agenesis of the teeth close to the cleft. Prevalence of cleft lip and palate varies from 1:500 to 1:2500 live births. Cleft lip and palate affect several systems and functions that include feeding, facial growth, dentition, mastication, deglutition, speech as well as social and psychological problems which have an impact on the child and parents.

Etiology includes either hereditary or environmental factors. Cleft lip and palate defects are genetically male sex-linked recessive. Environmental factors include influence of drugs like excessive use of steroids, viral infections, antibiotics insulin, antiepileptic drug and exposure to radiations in the first trimester of pregnancy. In 
infants with cleft lip and palate, feeding is very difficult which includes nasal regurgitation of food, excessive air intake which results in frequent choking and difficulty in closing their mouth around the nipple or the bottle to make a seal.

So an appliance that is favourable for feeding in these children i.e; a feeding obturator should be given. The main advantage of feeding appliance is that itcovers thecl eft palate and creates a platform towards which the infantcan press the nipple and sucks the milk. The present case report shows an infant with cleft lip and palate in which a feeding obturator was fabricated and inserted.

\section{Case Report}

A two-day old female neonate with unilateral cleft lip and palate was referred to the Department Of Pediatric And Preventive Dentistry, Kamineni Institute Of Dental College And Hospital, Narketpally, Nalgonda, Telangana with a chief complaint of difficulty in feeding. There was no history of orofacial clefts in maternal and paternal family of the child. On general examination, the neonate was found to be moderately built, with a birth weight of $2.8 \mathrm{~kg}$. Extra-oral examination of the child showed unilateral cleft lip on the left side (Figure 1). On intra oral examination, there was a large cleft on the left side of the alveolus and hard palate that extended to the soft palate. So it was decided to fabricate a feeding obturator. The advantages of feeding obturator were explained to the child's parents and the parents consent for the treatment plan was obtained.

\section{Fabrication of feeding obturator}

An infant acrylic impression tray was selected and intra-orally it was adjusted in accordance with the defect. Polyvinyl siloxane putty impression material was mixed and loaded impression tray was seated in child's mouth until theimpression material adequately covered the upper gum pads completely. Once the impression material was set, the tray was removed, and the mouth was examined for residual impression material.

Once the impression was obtained (Figure 2), a master cast was prepared and all the undercuts and the cleft space were blocked with wax. The feeding obturator was fabricated with self- cure acrylic material. Two retentive arms were made from 21 gauge stainless steel wire with tags at the end of wire component for retention of the feeding plate. To avoid trauma, all the borders of the appliance were rounded and polished and was checked for fit and retention. The appliance was placed in infant's oral cavity and patient's mother was asked to feed the baby and it was noted that there was no nasal regurgitation and child was successfully able to feed with the feeding obturator (Figure 3) without any discomfort. The micro pore tape had been used to stabilize the retentive arms and feeding plate. Parents were instructed and taught how to insert and remove the plate in oral cavity and how to feed the infant. Parents were instructed to maintain the oral hygiene of the infant and regarding cleaning of feeding plate.

\section{Presurgical Nasoalveolar Molding (PNAM)}

This includes the active molding and repositioning of the deformed nasal cartilages and alveolar processes as well as the lengthening of the columella. The nasal stent is added to the molding plate appliance so that nasal cartilage mol ding may begin which results in the correction of nasal cartilage deformity present in larger cleft defects. The nasal stent is a projection of acrylic that is fabricated on labial flange of molding plate. The stent is positioned inside the nose underneath the apex of alar cartilage on cleft side. The base of the stent should be located midway between the cleft lip segments (Figure 4).

The patient was recalled after 24 hours for any adjustment, and then the patient was followed up regularly for 3 months. During regular follow up, it was observed that there was an improvement in nutritional health status of the child.

\section{Discussion}

Neonates with a cleft palate have difficulty in feeding because the oro-nasal communication diminishes the ability to create negative pressure which is necessary for suckling. The feeding process is also complicated by nasal regurgitation of food, excessive air intake which leads to frequent choking. Feeding time is significantly longer which causes parental anxiety and it fatigues both baby as well as mother. ${ }^{1}$ 


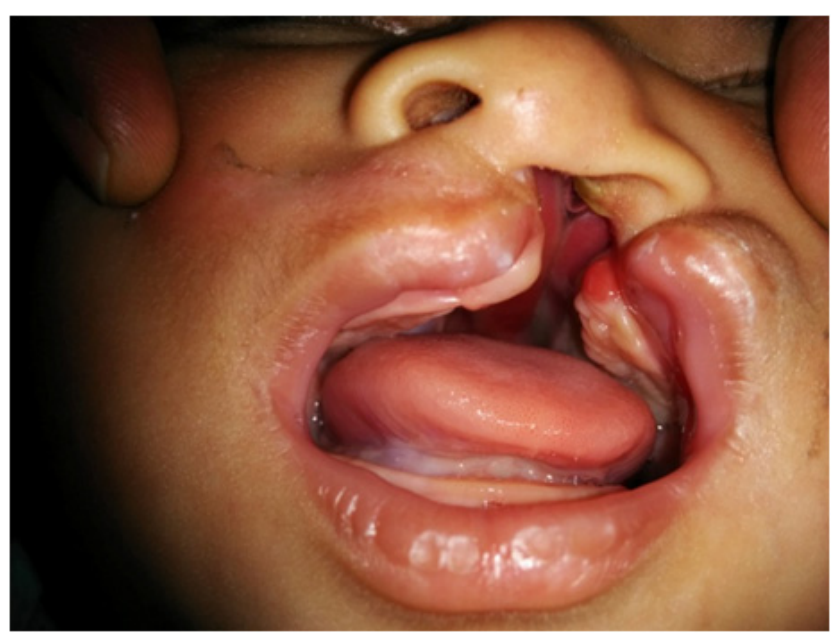

Figure 1: Clinical picture showing unilateral cleft lip and palate.

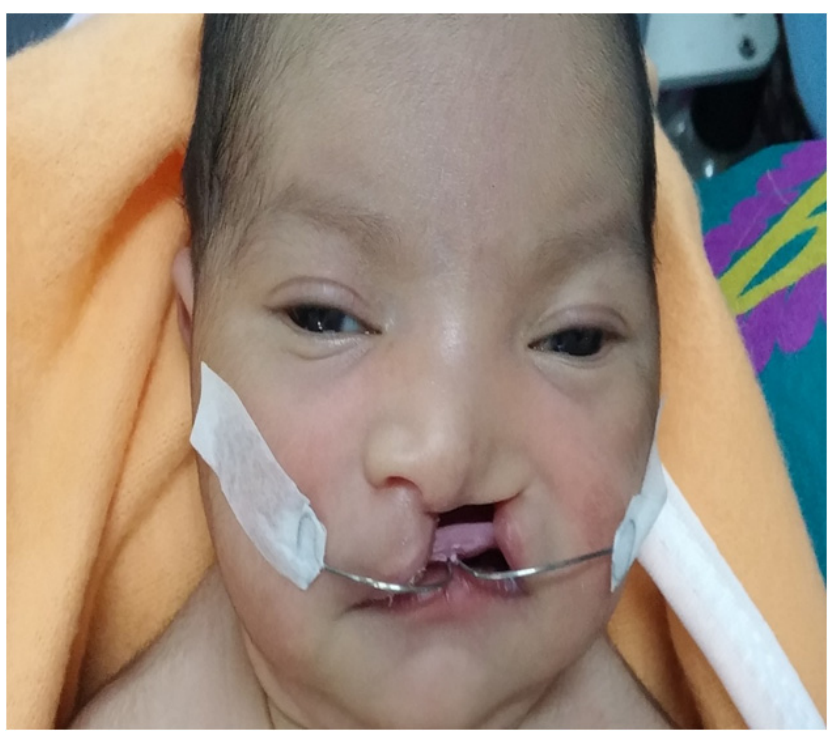

Figure 3: Feeding obturator

Surgery may completely close the inside the defect. However, timing of surgery differs may be as early as 10 to 12 weeks of age or 12 to 18 months. ${ }^{2}$ There are different feeding devices that can be very useful in successfully feeding an infant with a cleft lip and palate, like squeezable bottles, soft nipple, specially designed nipple with enlarged opening and wide based nipple. But they are not much useful for infants with large clefts. ${ }^{3}$

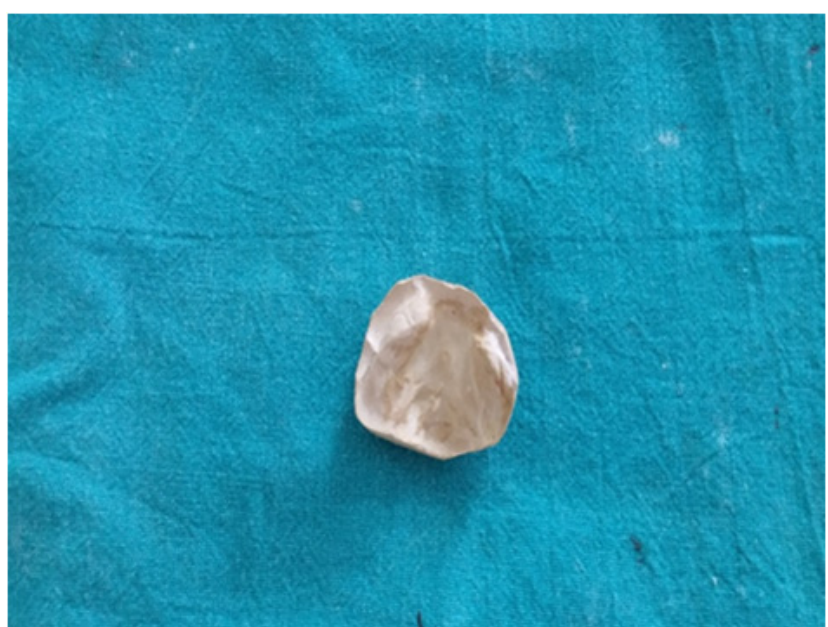

Figure 2: I mpression of cleft lip and palate

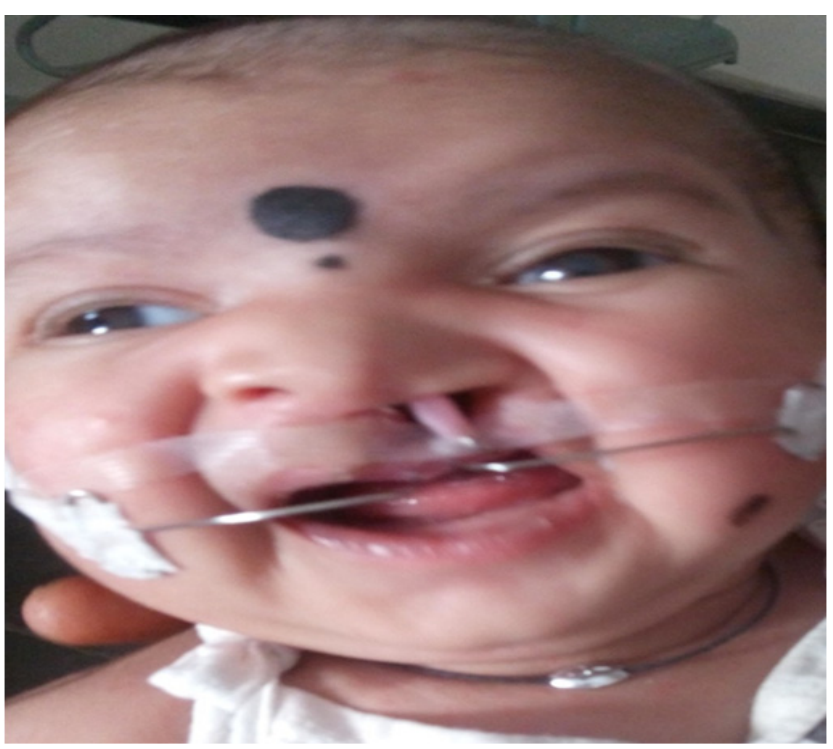

Figure 4: Feeding obturator with nasal stent.

A feeding obturator is an appliance that creates a seal between the oral and nasal cavities and controls the flow of milk. ${ }^{4}$ With this palatal obturator the baby can press the nipple and extract milk. It facilitates feeding, reduce nasal regurgitation and the incidence of choking, and shortens the length of thetime required for the feeding. The obturator also prevents the tongue from entering the defect and interfering with the spontaneous growth of the palatal shelves towards midline. ${ }^{5}$ Elastomeric 
impression materials are better suited for recording a cleft impression due to its good elastic behavior, high tear strength, accurate reproduction of surface details and long-term dimensional stability which allows multiple pour. ${ }^{6}$

In the present case, along with the obturator a nasal stent was added on the labial flange of feeding plate, a new approach which is called as pre-surgical nasoalveolar molding (PNAM). It helps in active molding and repositioning of the deformed nasal cartilages and alveolar processes, as well as lengthening of deficient columella. ${ }^{7}$ The main advantage of PNAM is its ability to guide the alveolar segments in to normal position prior to surgery. ${ }^{8}$

PNAM technique was first described by Grayson et al in 1993. Matsuo et al designed a nasal stent for the correction of nasal deformity. According to Spengler (2006) columella deviation, length and width of the nose have also significantly improved with PNAM.

J acobson (1967) described a technique using an acrylic obturator that engaged the undercut regions in the alveolar segments, which allowed passive molding of segments as growth developed. Latham (1980) described a pin-retained appliance that could rapidly close a unilateral cleft while advancing the lesser alveolar segment. ${ }^{8}$ In the present case, after the child had gained an adequate weight (more than $6 \mathrm{kgs}$ ), first surgical procedure was performed.

\section{Conclusion}

An appliance is required in almost all the cleft palate cases to create a seal between the nasal and oral cavity in order to create a negative pressure for feeding of infant. So, a feeding obturator is the appliance of choice as it creates this seal and also helps in reducing nasal regurgitation and choking. It is more beneficial to add a nasal stent along with the feeding obturator which is a new approach called Pre-surgical Naso-Alveolar Molding, this helps to guide the alveolar segments in to normal position prior to surgery.

\section{REFERECES:}

1. Narendra R, Sashi Purna CR, Reddy SD, Simhachalam Reddy N, Sesha Reddy P, Rajendra Prasad B. Feeding obturator-A presurgical prosthetic aid for infants with cleft lip and palate -clinical report. Ann Essences Dent 2013; 5(2):1-5.

2. Duggal A, Arora A, Duggal P, Handa K. Feeding obturator or appliance in a cleft palate patient: A case report. Ind J Compre Dent care 2014; 4(1):64-7.

3. Kummer AW. Cleft Palate and Craniofacial Anomalies. $2^{\text {nd }}$ ed. Clifton Park, NY: Thomson Delmar Learning; 2008.

4. Saunders ID, Geary I, Fleming P, Gregg TA. A simplified feeding appliance for the infant with a cleft lip and Palate. Quintesscence Int 1989; 20(12);907-10.

5. Savion I, Huband ML. A feeding obturator for a preterm baby with Piere Robin sequence. J Prosthet Dent 2005; 93:197-200.

6. Bansal R, Pathak AK, Bhatia B, Gupta S, Gautam KK. Rehabilitation of a One-day Old Neonate with Cleft Lip and Palate Using palatal Obturator: A Case Report. Int J Clin Pediatr Dent 2012; 5(2):145-7.

7. Sikligar S, Shah S, Mulchandani V, Rachappa MM, Dave B. A ray of hope in cleft lip and palate patients: case reports. Eur J Dent Therapy Res 2014; 3(2):217-20.

8. Grayson et al. Presurgical Alveolar Molding: Cleft Palate. Craniofacial J 1999; 36(6).

\section{Gain quick access to our journal online View our journal at www.nacd.in}

